\title{
DIAGNÓSTICO DA ARBORIZAÇÃO EM VIAS PÚBLICAS DOS BAIRROS CIDADE NOVA E CENTRO NA CIDADE DE RIO GRANDE - RS
}

\author{
AFFORESTATION DIAGNOSIS IN PUBLIC STREETS OF NEIGHBORHOODS \\ CIDADE NOVA AND CENTRO IN THE CITY OF RIO GRANDE - RS
}

Andreisa Damo¹, Sonia Marisa Hefler², Ubiratã Soares Jacobi³

\begin{abstract}
RESUMO
A arborização urbana relaciona-se diretamente à qualidade ambiental das cidades, proporcionando benefícios ecológicos e sociais. Esta pesquisa teve por objetivo realizar um diagnóstico da arborização em ruas dos bairros Cidade Nova e Centro no município de Rio Grande. As informações coletadas em campo buscaram identificar as espécies existentes, analisar a relação das árvores com instalações urbanas e suas condições fitossanitárias. Foram amostradas 1055 árvores, distribuídas em 52 espécies, sendo 69\% exóticas e 31\% nativas. Observou-se a dominância das espécies exóticas. O estado fitossanitário foi considerado bom, pois as árvores apresentaram valor menor que $30 \%$ para os critérios de fitossanidade avaliados, entretanto a presença de ramos epicórmicos foi observada em $65,6 \%$ dos indivíduos. A interferência com a fiação aérea foi verificada em $52,3 \%$ das árvores e com a calçada em $43,6 \%$, resultados que alertam para a necessidade de um planejamento adequado da escolha das espécies e sua relação com o espaço urbano e a infraestrutura existente.
\end{abstract}

Palavras-chave: Planejamento urbano; Condições fitossanitárias; Infraestrutura urbana.

\begin{abstract}
The urban afforestation is directly related to the environmental quality of the cities, providing ecological and social benefits. The main goal of this research was realize an afforestation diagnostic of the public roadways of neighborhoods Cidade Nova and Centro in the city of Rio Grande. The field collected information aimed to identify the species, analyze the relation between the trees and urban installations, and the phytosanitary conditions. There were sampled 1055 trees, distributed in 52 species, of those $69 \%$ exotics and $31 \%$ natives. It was observed the dominance of the exotics species. The phytosanitary condition was considered good, because the trees showed values lower than $30 \%$ for the phytosanitary criteria evaluated, however the presence of epicormics branches was observed in $65,6 \%$ of the subjects. The interference in electric wire lines was verified in $52,3 \%$ of the trees while the conflict with sidewalks in $43,6 \%$, results that alert to the necessity for an adequate planning on the choosing of species in relation to the urban space and the existing infrastructure.
\end{abstract}

Key-words: Urban planning; Phytosanitary condition; Urban infrastructure.

Recebido em 09.06.2015 e aceito em 15.09.2015

1 Bióloga, Doutoranda do Programa de Pós-graduação em Educação Ambiental da Universidade Federal do Rio Grande FURG, Rio Grande/RS. Email: andreisafdamo@gmail.com

2 Bióloga, Dra, Professora do Instituto de Ciências Biológicas da Universidade Federal do Rio Grande - FURG, Rio Grande/RS. Email: soniahefler@furg.br

3 Biólogo, Dr, Professor do Instituto de Ciências Biológicas da Universidade Federal do Rio Grande - FURG, Rio Grande/RS., Email: dmbbira@furg.br 


\section{INTRODUÇÃO}

A arborização urbana está associada à manutenção da qualidade ambiental nas cidades e ao bem estar das populações que as habitam. Os benefícios comumente associados à presença de cobertura vegetal são a regulação das condições microclimáticas, redução da poluição atmosférica, fornecimento de sombra, produção de frutos para a avifauna, com especial destaque para os pássaros que podem ser importantes predadores exercendo o controle do tamanho populacional de pragas e de vetores de doenças (ROPPA et al., 2007). Bobrowski e Biondi (2012) asseguram que as cidades com boa cobertura vegetal são menos suscetíveis à ação das chuvas torrenciais, já que a presença de árvores permite a infiltração da água da chuva, diminui o escoamento superficial e estabiliza o solo, reduzindo as chances de ocorrer deslizamentos, erosões e enchentes.

Todavia, para o pleno aproveitamento dos benefícios referidos e do papel indispensável do componente arbóreo para a qualidade ambiental das cidades e o bem estar de seus moradores, deve-se atentar para a importância de haver planejamento adequado da criação, manutenção e manejo de áreas arborizadas. O plantio de árvores inadequadas à estrutura urbana gera conflitos com fiações elétricas, encanamentos, calhas, calçamentos, muros, postes de iluminação, etc. Assim, o planejamento da arborização precisa aliar as características das espécies vegetais ao espaço urbano disponível, a fim de evitar conflitos com a infraestrutura das cidades e entre as próprias árvores, considerando também aspectos como a diversidade das espécies e a ocorrência regional das mesmas, de forma a garantir o aumento da vida útil da planta (SALVI et al., 2011).

Com relação à diversidade de espécies, a falta de planejamento pode trazer consequências indesejáveis, ao sinalizar o fato de que a uniformização da vegetação urbana constitui grande perigo, já que a diversidade de espécies vegetais é condição básica para a sobrevivência da fauna e o equilíbrio ecológico (SALVI et al., 2011). A predominância de poucas espécies na arborização de uma cidade traz sérias consequências para o ecossistema urbano, haja vista que a diversidade da vegetação é de suma importância para a ampliação e fixação da fauna, a manutenção do equilíbrio biológico e o controle de pragas.

É essencial também priorizar as espécies nativas de cada região no planejamento da arborização urbana, a fim de evitar danos ambientais associados à presença de espécies exóticas, como a perda da biodiversidade e a alteração da paisagem natural. Um planejamento adequado da arborização urbana deve dar preferência às espécies nativas, 
adaptadas ao habitat regional e adequadas ao local onde serão plantadas (BARROS et al., 2010).

Como visto, os fatores que indicam a importância da arborização urbana, além daqueles que denotam a necessidade de uma escolha criteriosa das espécies nativas da região e dos procedimentos para a criação, a conservação e o manejo destas áreas sinalizam para a necessidade de empenho da gestão pública municipal. Estas ações devem ter em vista as demandas que se evidenciam para a população e o ambiente local, de priorizar a arborização urbana na forma de planos diretores, baseados em diretrizes que visam orientar a adequada realização da criação e conservação de áreas verdes municipais. Nesse intuito, os estudos de diagnóstico da arborização urbana constituem-se em importante ferramenta para contribuir com este planejamento adequado (KRAMER; KRUPEK, 2012).

Desse modo, esta pesquisa teve por objetivo realizar o diagnóstico da arborização urbana em vias públicas dos bairros Cidade Nova e Centro na cidade de Rio Grande/RS. Para tal, buscou-se elaborar listagem florística das espécies utilizadas na arborização viária, com dados da sua origem, estado fitossanitário e a existência de conflitos com a infraestrutura urbana, tendo em vista fornecer subsídios aos serviços públicos e à comunidade, no que tange ao manejo e ao planejamento da arborização.

\section{MATERIAL E MÉTODOS}

A cidade do Rio Grande está localizada na Planície Costeira do extremo Sul do Brasil, nas coordenadas $32^{\circ} 02^{\prime} 06^{\prime \prime}$ S e $52^{\circ} 05^{\prime} 56^{\prime \prime} \mathrm{W}$. Seu território compreende uma faixa de terras baixas, na restinga do Rio Grande, a Sudoeste da desembocadura da Lagoa dos Patos. A vegetação diversifica-se em ambientes típicos de restinga, com os ecossistemas dos banhados, lagos, florestas de restinga, campos, marismas e as formações de dunas (JACOBI et al., 2013).

A coleta de informações nesse estudo deu-se em duas etapas: na primeira, realizada em 2012, fez-se o inventário das espécies arbóreas existentes em quatro vias públicas do Bairro Cidade Nova, distribuídas nas direções leste-oeste, e norte-sul, de forma a representar adequadamente o padrão de arborização (Figura 1); nestas vias, os indivíduos foram avaliados no diagnóstico do estado da arborização (I.A.D) quanto às condições fitossanitárias e sua relação com as instalações urbanas. Na segunda etapa, realizada em 2013 nos bairros Centro e Cidade Nova, os indivíduos foram apenas inventariados (I.A.I), de modo a fornecer listagem florística complementar ao diagnóstico anteriormente realizado. 


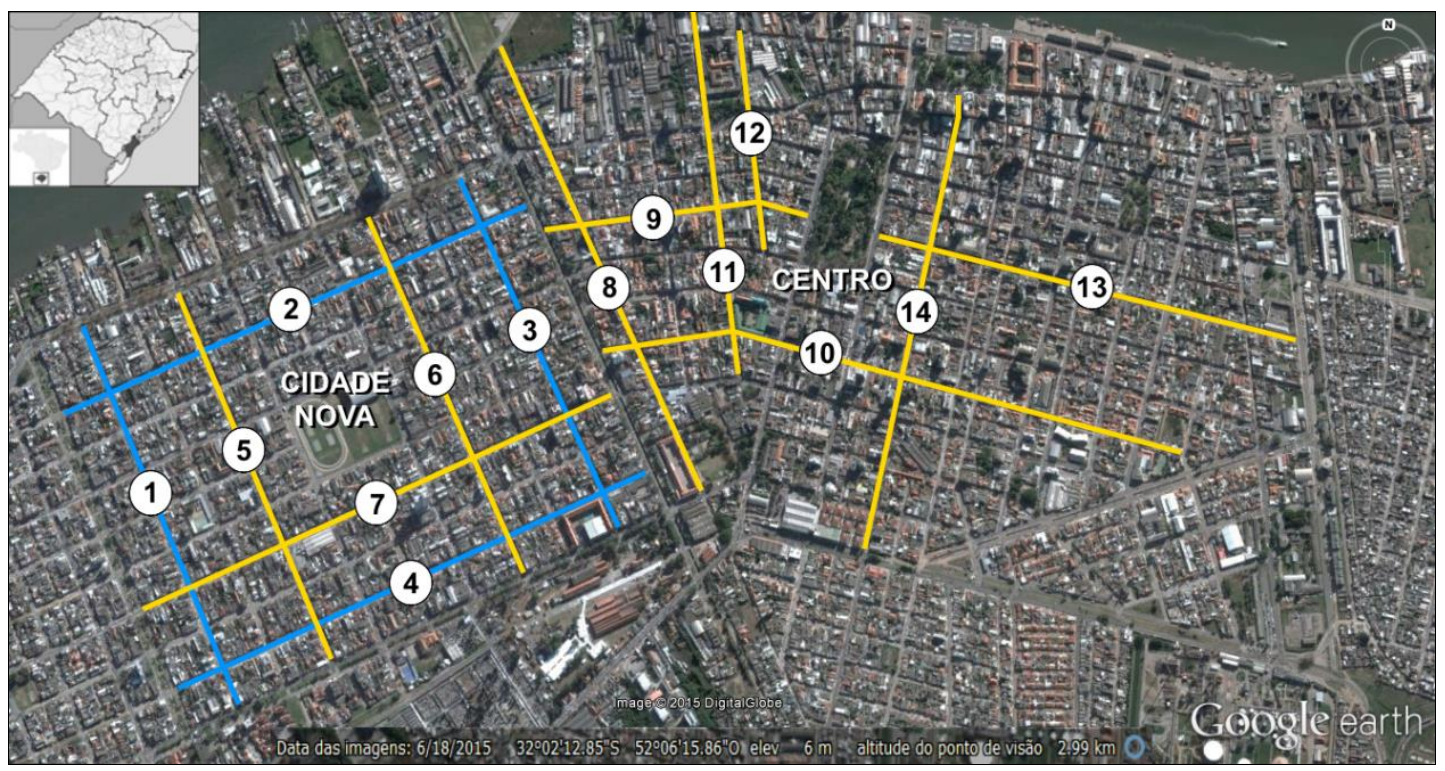

NOTA: 1) Rua República; 2) Rua Visc. de Mauá; 3) Rua Mal. Deodoro; 4) Rua Gen. Abreu; 5) R. Marcílio Dias; 6) R. Caramuru; 7) R. Dom Bosco; 8) R. Moron; 9) R. Carlos Gomes; 10) R. Barão de Cotegipe; 11) R. Gen. Canabarro; 12) R. Visc. de Paranaguá; 13) R. Gen. Câmara; 14) R. Duque de Caxias

Figura 1. Vista aérea do Município do Rio Grande, mostrando os bairros Cidade Nova e Centro com o destaque, em linhas azuis, das ruas onde foi realizado o diagnóstico do estado da arborização. Em amarelo, as ruas nas quais se realizou o inventário florístico complementar

Figure 1. Aerial view of the city of Rio Grande, showing the neighborhoods Cidade Nova and Centro with the highlight, in blue line, of the streets where it was realized the diagnosis of the afforestation condition. In yellow, the streets in which they held the additional floristic inventory

A escolha dos bairros Cidade Nova e Centro justifica-se pelo fato de apresentarem a maior densidade demográfica de Rio Grande e também em razão de sua importância histórico-patrimonial, ligada à colonização portuguesa que influenciou aspectos das construções urbanas importantes do ponto de vista da arborização, como a conformação das ruas e calçadas, as quais tendem a ser muito estreitas e, portanto, pouco receptivas à vegetação, o que resultou em espaços pouco arborizados, característicos também dos demais bairros do município. Justamente em razão disso, a seleção das ruas para o inventário priorizou aquelas mais arborizadas, a fim de obter amostra mais expressiva da composição florística utilizada na cidade, bem como a visualização mais clara dos conflitos com instalações urbanas.

Os indivíduos arbóreos encontrados foram identificados ao nível taxonômico de espécie determinando-se a riqueza e a quantidade total de indivíduos. O diagnóstico do estado da arborização das ruas foi realizado de acordo com critérios elaborados a partir do Plano Diretor de Arborização Urbana de Porto Alegre (SMAM, 2007): distância do colo até a face interna do meio fio da calçada, distância do início da rua até a primeira árvore, distância 
em relação à árvore posterior e distância da última árvore inventariada até o final da rua, interferência com instalações urbanas (fiação aérea e calçamento), condições fitossanitárias: estado da copa em relação à existência de ramos epicórmicos e de galhos em decomposição; estado do fuste no que tange à existência de fendas e tumorações decorrentes de injúrias mecânicas ou doenças; infestação por hemiparasitas; afloramento do sistema radicular e existência de poda, com identificação no caso do tipo drástica.

O percentual de interferência com as calçadas foi calculado sobre indivíduos arbóreos, excluindo os dos canteiros centrais que não possuem pavimentação. O percentual de interferência com a fiação aérea foi calculado sobre as árvores encontradas nos lados das ruas que apresentam fiação e excluindo as existentes nos canteiros centrais, tendo em vista que nestes a fiação não acompanha a arborização, mas a atravessa perpendicularmente evitando conflitos.

As espécies conhecidas foram identificadas no local, e as demais com o auxílio de bibliografia especializada, chaves analíticas e consulta a especialistas. Quanto à origem fitogeográfica das espécies, foram consideradas nativas aquelas de origem no território brasileiro, destacando as de ocorrência no Rio Grande do Sul, em razão de sua especial importância para o uso na arborização das cidades do estado, visando a conservação da diversidade arbórea.

A classificação da origem fitogeográfica e os nomes científicos das espécies foi feita com base em Lorenzi (2014a), Lorenzi (2014b) e Lorenzi et al. (2003). A delimitação dos táxons, no nível de família, seguiu a proposição da Angiosperm Phylogeny Group III (APG III, 2009) para as angiospermas.

\section{RESULTADOS E DISCUSSÃO}

No presente estudo foram amostrados 1055 indivíduos arbóreos, distribuídos em 52 espécies e 23 famílias botânicas (Tabela 1a; Tabela 1b). Das espécies inventariadas, 69\% são exóticas e $31 \%$ são nativas. As espécies mais abundantes foram Platanus $x$ acerifolia com $27 \%$ do total de indivíduos amostrados e Jacaranda mimosifolia, com $25 \%$, seguido por Melia azedarach (10,7\%), Ligustrum lucidum (4,9\%), Schinus terebinthifolius (4,2\%), Populus nigra (3,9\%) e Tipuana tipu (3,3\%), todas exóticas, com exceção de $S$. terebinthifolius (aroeira-vermelha). As demais espécies registradas não alcançaram individualmente $3 \%$ do total de indivíduos amostrados. 
Tabela 1. Listagem de espécies, seguida por famílias, origem fitogeográfica (RS: nativa do Rio Grande do Sul; BR: nativa do Brasil; E: exótica) e número de indivíduos por espécie avaliados no diagnóstico do estado da arborização (I.A.D) e indivíduos apenas inventariados (I.A.I)

Table 1. Listing of species, followed by families, phytogeographic origin (RS: native of Rio Grande do Sul, BR: native of Brazil, E: exotic) and number of individuals (Ind.) by species

\begin{tabular}{|c|c|c|c|c|c|}
\hline Família & Nome científico & Nome popular & Origem & I.A.D & I.A.I \\
\hline Anarcadiaceae & Schinus molle L. & aroeira-salso & RS & - & 1 \\
\hline Anarcadiaceae & Schinus terebinthifolius Raddi & aroeira-vermelha & RS & 13 & 31 \\
\hline Apocynaceae & Nerium oleander L. & espirradeira & $\mathrm{E}$ & 5 & 6 \\
\hline Apocynaceae & Thevetia peruviana (Pers.) K. Schum. & $\begin{array}{l}\text { chapéu-de- } \\
\text { napoleão }\end{array}$ & $\mathrm{BR}$ & 1 & - \\
\hline Araliaceae & Schefflera actinophylla (Endl.) Harms & guarda-chuva & $\mathrm{E}$ & - & 1 \\
\hline Araliaceae & Schefflera arboricola (Hayata) Merr. & cheflera & $E$ & - & 9 \\
\hline Araucariaceae & Araucaria angustifolia (Bertol.) Kuntze & araucária & RS & - & 1 \\
\hline Arecaceae & $\begin{array}{l}\text { Archontophoenix cunninghamiana } \mathrm{H} \text {. } \\
\text { Wendl. \& Drude }\end{array}$ & palmeira-real & $\mathrm{E}$ & - & 2 \\
\hline Arecaceae & $\begin{array}{l}\text { Butia odorata (Barb. Rodr.) Noblick \& } \\
\text { Lorenzi }\end{array}$ & butiazeiro & RS & 1 & 2 \\
\hline Arecaceae & Phoenix canariensis Chabaud & $\begin{array}{l}\text { palmeira-das- } \\
\text { canárias }\end{array}$ & $E$ & - & 11 \\
\hline Arecaceae & $\begin{array}{l}\text { Syagrus romanzoffiana (Cham.) } \\
\text { Glassman }\end{array}$ & jerivá & RS & - & 1 \\
\hline Bignoniaceae & Catalpa bignonioides Walter & catalpa & $\mathrm{E}$ & - & 12 \\
\hline Bignoniaceae & Jacaranda mimosifolia D. Don & jacarandá-mimoso & $\mathrm{E}$ & 109 & 159 \\
\hline Bignoniaceae & $\begin{array}{l}\text { Handroanthus chrysotrichus (Mart. ex } \\
\text { DC.) Mattos }\end{array}$ & ipê-amarelo & $\mathrm{BR}$ & 1 & 2 \\
\hline Bignoniaceae & $\begin{array}{l}\text { Handroanthus heptaphyllus (Vell.) } \\
\text { Mattos }\end{array}$ & ipê-roxo & RS & 3 & 1 \\
\hline Casuarinaceae & Casuarina equisetifolia L. & casuarina & $\mathrm{E}$ & - & 1 \\
\hline Ebenaceae & Diospyros kaki Thunb. & caquizeiro & $E$ & 1 & - \\
\hline Euphorbiaceae & Euphorbia cotinifolia L. & leiteiro-vermelho & $\mathrm{E}$ & 2 & - \\
\hline Euphorbiaceae & $\begin{array}{l}\text { Euphorbia pulcherrima Willd. ex } \\
\text { Klotzsch }\end{array}$ & poinsétia & $E$ & - & 2 \\
\hline Fabaceae & Acacia mearnsii De Wild. & acácia -negra & $\mathrm{E}$ & 1 & - \\
\hline Fabaceae & Bauhinia variegata $\mathrm{L}$. & pata-de-vaca & $\mathrm{E}$ & - & 1 \\
\hline Fabaceae & Leucaena leucocephala (Lam.) de Wit & leucena & $\mathrm{E}$ & 1 & - \\
\hline Fabaceae & Parapiptadenia rigida (Benth.) Brenan & angico-vermelho & RS & 1 & - \\
\hline Fabaceae & Peltophorum dubium (Spreng.) Taub. & canafístula & RS & 5 & - \\
\hline Fabaceae & $\begin{array}{l}\text { Senna pendula (Humb. \& Bonpl. ex } \\
\text { Willd.) H. S. Irwin \& Barneby }\end{array}$ & canudo-de-pito & RS & 5 & 13 \\
\hline Fabaceae & Tipuana tipu (Benth.) Kuntze & tipuana & $\mathrm{E}$ & 1 & 34 \\
\hline Lauraceae & Cinnamomum zeylanicum Blume & caneleira & E & - & 1 \\
\hline Lauraceae & Persea americana Mill. & abacateiro & $\mathrm{E}$ & - & 2 \\
\hline Lythraceae & Lagerstroemia indica L. & extremosa & $\mathrm{E}$ & 3 & 3 \\
\hline Malvaceae & Ceiba speciosa (A. St.-Hil.) Ravenna & paineira-rosa & RS & 1 & 2 \\
\hline Malvaceae & Luehea divaricata Mart. & açoita-cavalo & RS & 1 & - \\
\hline Meliaceae & Melia azedarach L. & cinamomo & $E$ & 17 & 96 \\
\hline Moraceae & Ficus benjamina L. & figueira-de-jardim & E & 11 & 18 \\
\hline Moraceae & Ficus elastica Roxb. ex Hornem & falsa-seringueira & $E$ & - & 4 \\
\hline Moraceae & Ficus organensis Miq. & figueira-branca & RS & 1 & 5 \\
\hline
\end{tabular}


...Continuação

\begin{tabular}{|c|c|c|c|c|c|}
\hline Família & Nome científico & Nome popular & Origem & I.A.D & I.A.I \\
\hline Moraceae & Morus nigra L. & amoreira & $\mathrm{E}$ & 1 & 1 \\
\hline Myrtaceae & Eucalyptus grandis W. Hill & eucalipto & $\mathrm{E}$ & 1 & - \\
\hline Myrtaceae & Eugenia uniflora L. & pitanqueira & RS & 1 & 1 \\
\hline Myrtaceae & Psidium cattleyanum Sabine & araçazeiro & RS & 2 & 1 \\
\hline Myrtaceae & Psidium guajava L. & goiabeira & E & 1 & 1 \\
\hline Myrtaceae & Syzygium cumini (L.) Skeels & jambolão & $\mathrm{E}$ & 3 & 10 \\
\hline Oleaceae & Ligustrum lucidum W. T. Aiton & ligustro & $E$ & 9 & 43 \\
\hline Oleaceae & Olea europaea L. & oliveira & $\mathrm{E}$ & 7 & 3 \\
\hline Pinaceae & Pinus elliottii Engelm. & pinus & $E$ & - & 2 \\
\hline Platanaceae & Platanus $x$ acerifolia (Aiton) Willd. & plátano & $E$ & 70 & 216 \\
\hline Rhamnaceae & Hovenia dulcis Thunb. & uva-japonesa & $E$ & 1 & 4 \\
\hline Rosaceae & Eriobotrya japonica (Thunb.) Lindl. & nespereira & $\mathrm{E}$ & - & 1 \\
\hline Rutaceae & Citrus $x$ limonia (L.) Osbeck & limão-cravo & $\mathrm{E}$ & 1 & 1 \\
\hline Rutaceae & Citrus $x$ sinensis (L.) Osbeck & laranjeira & $E$ & - & 1 \\
\hline Rutaceae & Citrus reticulata Blanco & bergamoteira & $E$ & - & 1 \\
\hline Salicaceae & Populus nigra L. & álamo & $\mathrm{E}$ & 24 & 17 \\
\hline Salicaceae & Salix babylonica L. & salgueiro-chorão & $E$ & 6 & 20 \\
\hline
\end{tabular}

Das espécies inventariadas, 17 apresentaram apenas um indivíduo cada (1,61\% do total), os quais foram considerados plantios irregulares porque possivelmente foram realizados pelos próprios moradores, nas proximidades de suas residências, a exemplo das frutíferas Diospyros kaki (caquizeiro), Citrus $x$ sinensis (laranjeira) e Citrus reticulata (bergamoteira).

Observou-se desequilíbrio na distribuição dos indivíduos por espécie, pois duas árvores exóticas, Platanus $x$ acerifolia e Jacaranda mimosifolia, dominaram significativamente a amostra em termos de abundância, perfazendo juntas $52 \%$ do total, caracterizando a homogeneização da arborização nas ruas inventariadas. Os valores encontrados excedem o parâmetro aceitável de 15\% em relação à abundância de cada espécie em uma mesma cidade baseada em recomendações da International Society of Arboriculture (2015), sugerindo observar os riscos associados à homogeneização da vegetação, como a maior suscetibilidade ao ataque de pragas.

A homogeneização no plantio foi mais evidente nas ruas General Câmara e Carlos Gomes (bairro Centro), nas quais Platanus $x$ acerifolia dominou a amostra. De acordo com Kramer e Krupek (2012), a maioria das cidades brasileiras apresenta a composição arbórea pouco diversificada, constituindo-se, muitas vezes, de monocultivos onde as espécies exóticas predominam. Os autores alertam ainda que a homogeneização da vegetação pode contribuir para a perda do equilíbrio ecológico, condição básica à diversidade das espécies (KRAMER; KRUPEK, 2012). A diversidade de espécies vegetais, sobretudo as nativas, é importante, de acordo com Palazzo Junior e Both (1989), porque promove a manutenção da 
fauna, contribuindo também para o controle de pragas. Assim, é importante que o planejamento e a execução dos projetos de arborização incluam a diversidade vegetal, Schinus terebinthifolius foi a espécie nativa que apresentou o maior número de indivíduos (44), entretanto muito insignificante se comparado às duas espécies exóticas dominantes (554). Esta espécie apresenta um porte adequado à arborização de ruas, mesmo sob fiação (LORENZI, 2014a). A espécie também pode ser útil na conservação dos ecossistemas, já que suas flores são melíferas, e os frutos são muito procurados pela avifauna, além de serem utilizados na alimentação humana como condimento (LORENZI, 2014a), possibilitando a obtenção de renda com seu cultivo.

Outras espécies nativas inventariadas neste estudo poderiam ser incluídas em projetos futuros de arborização urbana ou no manejo das áreas já existentes no município, quando houver a necessidade de substituir árvores em razão de doenças ou conflitos com a infraestrutura. Duas palmeiras nativas, Butia odorata e Syagrus romanzoffiana, podem ser privilegiadas, no lugar das exóticas, sendo colocadas preferencialmente em praças, e ruas sem fiação, pois além de serem ornamentais, fornecem frutos úteis à alimentação humana e à fauna urbana.

Outros exemplos de nativas que podem compor a arborização viária são as frutíferas de pequeno porte Eugenia uniflora e Psidium cattleianum. Para ornamentação e sombreamento em vias públicas espaçosas ou áreas amplas, como jardins, praças e parques, são adequadas as espécies de grande porte Ficus organensis (figueira), Handroanthus heptaphyllus (ipê-roxo), Parapiptadenia rigida (angico-vermelho) e Peltophorum dubium (canafístula).

Em razão de terem sido registrados poucos indivíduos de espécies nativas, os dados apresentados não são conclusivos quanto à suscetibilidade destas espécies ao estresse gerado pelo ambiente urbano, entretanto Butia odorata e Syagrus romanzoffiana resistem bem neste ambiente.

A relação de espécies e indivíduos de acordo com a origem fitogeográfica apontou a dominância de exóticas (36 espécies somando 958 indivíduos) sobre as nativas (16 espécies e 97 indivíduos). Tendo em vista estes valores, a composição da arborização nas ruas inventariadas não é equilibrada, pois as árvores exóticas, além de dominarem a amostra em número de espécies, também foram predominantes em relação à quantidade de indivíduos.

Outros trabalhos também demonstraram a desarmonia na distribuição de espécies e indivíduos, indicando falta de planejamento da arborização urbana. Em um estudo realizado na cidade de Patos-PB, uma única espécie exótica deteve quase $70 \%$ dos indivíduos inventariados (MELO; LIRA FILHO; RODOLFO JÚNIOR, 2007). Na cidade de 
Lavras da Mangabeira-CE, três espécies exóticas perfizeram 92,95\% dos 2784 indivíduos amostrados, indicando elevada homogeneização da arborização e evidenciando a prevalência de exóticas com relação às nativas da flora brasileira (CALIXTO JÚNIOR; SANTANA; LIRA FILHO, 2009) ou mostrando elevado número de espécies, porém com baixo número de indivíduos.

Por outro lado, um estudo realizado por Batistel et al. (2009) em Quirinópolis-GO, registrou que uma única espécie (Licania tomentosa (Benth.) Fritsch), nativa do Brasil e conhecida popularmente como oiti, deteve $86,9 \%$ dos indivíduos inventariados. De acordo com Silva et al. (2008b), embora seja comum na arborização urbana que poucas espécies representem a maior parte da população, esta não é uma situação desejável, por razões estéticas ou fitossanitárias.

Apesar do registro de 16 espécies nativas na arborização das ruas amostradas, nota-se um baixo número de indivíduos distribuídos entre estas espécies, com apenas 9,2\% do total, o que foi também observado no trabalho de Romani et al. (2012). Distintamente, Raber e Rebelato (2010) em estudo realizado na cidade de Colorado-RS, registraram a predominância de espécies nativas na arborização da cidade, com 25 de um total de 45 espécies, totalizando $51 \%$ dos indivíduos amostrados; estes valores podem ser considerados satisfatórios, tendo em vista que, dentre as espécies arbóreas mais cultivadas em áreas urbanas no Brasil, apenas 20\% são nativas (LORENZI, 1999). Muitas espécies exóticas são preferidas para este fim, por motivos como seu rápido crescimento e facilidade na obtenção das sementes. Isso pode ser explicado pelo desconhecimento do potencial que certas plantas nativas apresentam para 0 emprego na arborização de ruas, avenidas, praças, parques e demais ambientes urbanos. Além disso, há também o "modismo" e a falta de interesse na conservação da flora regional, que leva à preferência pelo uso de espécies exóticas para fins arborísticos (KRAMER; KRUPEK, 2012).

Entre as exóticas predominantes na arborização da cidade de Rio Grande, Platanus $x$ acerifolia apresentou a maior quantidade de indivíduos do total amostrado. Estudo realizado em Campos do Jordão-SP revelou que, apesar de terem sido registradas 32 espécies, mais da metade da cidade (53,7\%) é arborizada com plátanos (ANDRADE, 2002). Segundo Lorenzi et al. (2003), o plantio do plátano é recomendado para grandes espaços, devido a sua copa ser muito vistosa; assim, quando utilizado em ruas estreitas, pode acarretar a necessidade de poda constante, para evitar que a copa interfira nas estruturas urbanas. Os plátanos são plantas potencialmente alergógenas, pois seus frutos são pequenos, leves e revestidos de pelos, sendo transportados pelo vento; com isso, 
dispersam-se no ar, podendo provocar reações alérgicas nos olhos e vias respiratórias. Isso evidencia a importância de haver seleção adequada das espécies que vão constituir a arborização das cidades, através da escolha de plantas seguras, livres de componentes tóxicos ou alergênicos e que não ofereçam riscos à saúde da população (LORENZI et al., 2003).

Melia azedarach é uma espécie bem adaptada no território brasileiro, ocorrendo nas regiões sul e sudeste (LORENZI et al., 2003) sendo assim classificada como subespontânea. No entanto, pode ser considerada invasora em certos ambientes, crescendo de forma agressiva em florestas subtropicais ao longo de rios, o que exige cuidados em razão da possibilidade de haver competição com espécies nativas acarretando desequilíbrios ambientais.

A desarmonia quanto à origem fitogeográfica, tanto em número de espécies quanto de indivíduos, observada no inventário das vias públicas amostradas em Rio Grande aponta para o poder público a necessidade de planejamento adequado da arborização futura e do manejo das árvores já existentes, tendo em vista os benefícios ambientais que a flora nativa pode proporcionar (ALMEIDA; NETO, 2010; BARROS et al., 2010; KRAMER; KRUPEK, 2012; ROMANI et al., 2012; SALVI et al., 2011; SOUZA et al., 2011), em comparação à de origem exótica, já que, além de estar mais bem adaptada às características do ambiente local, também contribui para o estabelecimento da fauna, principalmente de aves, melhorando a qualidade ambiental das cidades.

O diagnóstico das condições da arborização urbana nas quatro vias analisadas neste estudo mostra que os indivíduos arbóreos foram considerados em bom estado de conservação quanto às condições fitossanitárias, pois os critérios utilizados para o diagnóstico do estado fitossanitário, existência de tumorações, galhos em decomposição e existência de fendas, que indicam condições da copa e do fuste, e também a existência de hemiparasitas e afloramento da raiz, apresentaram valores que não excedem aos $30 \%$ (Figura 2) das árvores amostradas. A infestação por hemiparasitas foi baixa (8,7\%) (Figura 2), afetando quase exclusivamente os plátanos amostrados nos canteiros centrais.

Por outro lado, ao ser avaliada a existência de ramos epicórmicos na copa, observou-se que 204 (65,6\%) (Figura 2) das árvores apresentaram esta condição, entre estas, destacam-se os indivíduos de Populus nigra (Figura 3a) e Jacaranda mimosifolia. Este resultado sugere que não houve uma escolha planejada da espécie para plantio nas ruas, especialmente em relação ao porte das árvores, o que veio exigir poda constante, algumas vezes do tipo drástica, principalmente abaixo de redes de fiação aérea, não excluindo a possibilidade de má execução da poda, prática que favorece a formação de ramos epicórmicos. 


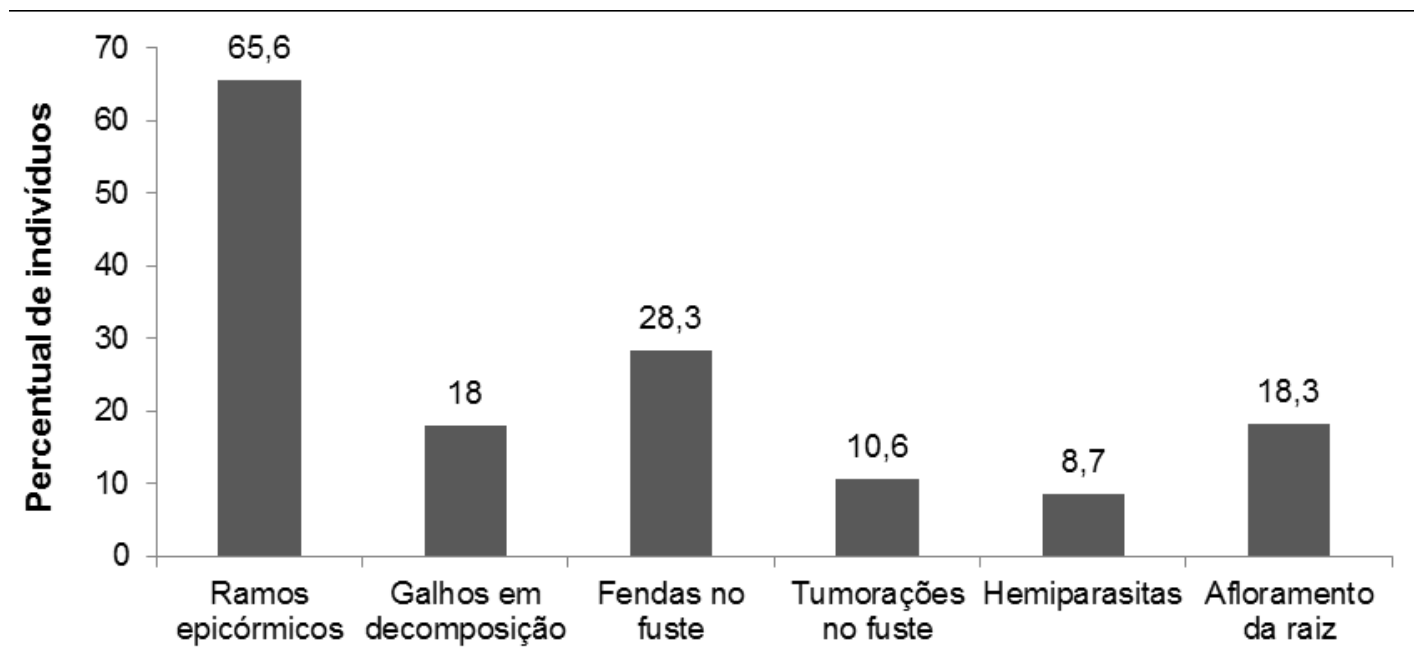

Condições fitossanitárias

Figura 2. Percentual de indivíduos em relação às condições fitossanitárias

Figure 2. Percentage of individuals in relation to the phytosanitary conditions

De acordo com Salvi et al. (2011) a formação de ramos epicórmicos indica uma reação da planta à poda malfeita, na tentativa de recompor sua folhagem original. Esses ramos precisam ser eliminados, mas podem ser prevenidos com podas menos severas realizadas com a planta ainda jovem.

O presente estudo demonstrou que apenas $21,2 \%$ dos indivíduos arbóreos apresentaram as copas íntegras, sem podas. Os demais receberam poda drástica (21,9\%) (Figura 3b), ou outro tipo de poda (56,9\%). A poda deve ser feita apenas para galhos secos, doentes ou mal colocados, e a poda de formação, em mudas, para que possam atingir um fuste de aproximadamente dois metros de altura, evitando assim futuras mutilações, logicamente se o plantio for feito de forma correta.

Quanto à interferência das árvores com as instalações urbanas, 43,6\% dos indivíduos apresentaram conflito com as calçadas, na forma de rupturas, elevações e deformações na pavimentação, entre estes, destaca-se a espécie de grande porte Platanus $x$ acerifolia (Figura 3c). Conflitos com calçadas foram também verificados por Silva et al. (2008a), relacionados a uma espécie de grande porte (Tipuana tipu), perfazendo 45,9\% dos danos registrados na amostragem. Estes conflitos ocorrem por fatores como a inadequação das espécies para a arborização viária e espaço livre insuficiente nas calçadas para o desenvolvimento das árvores. 


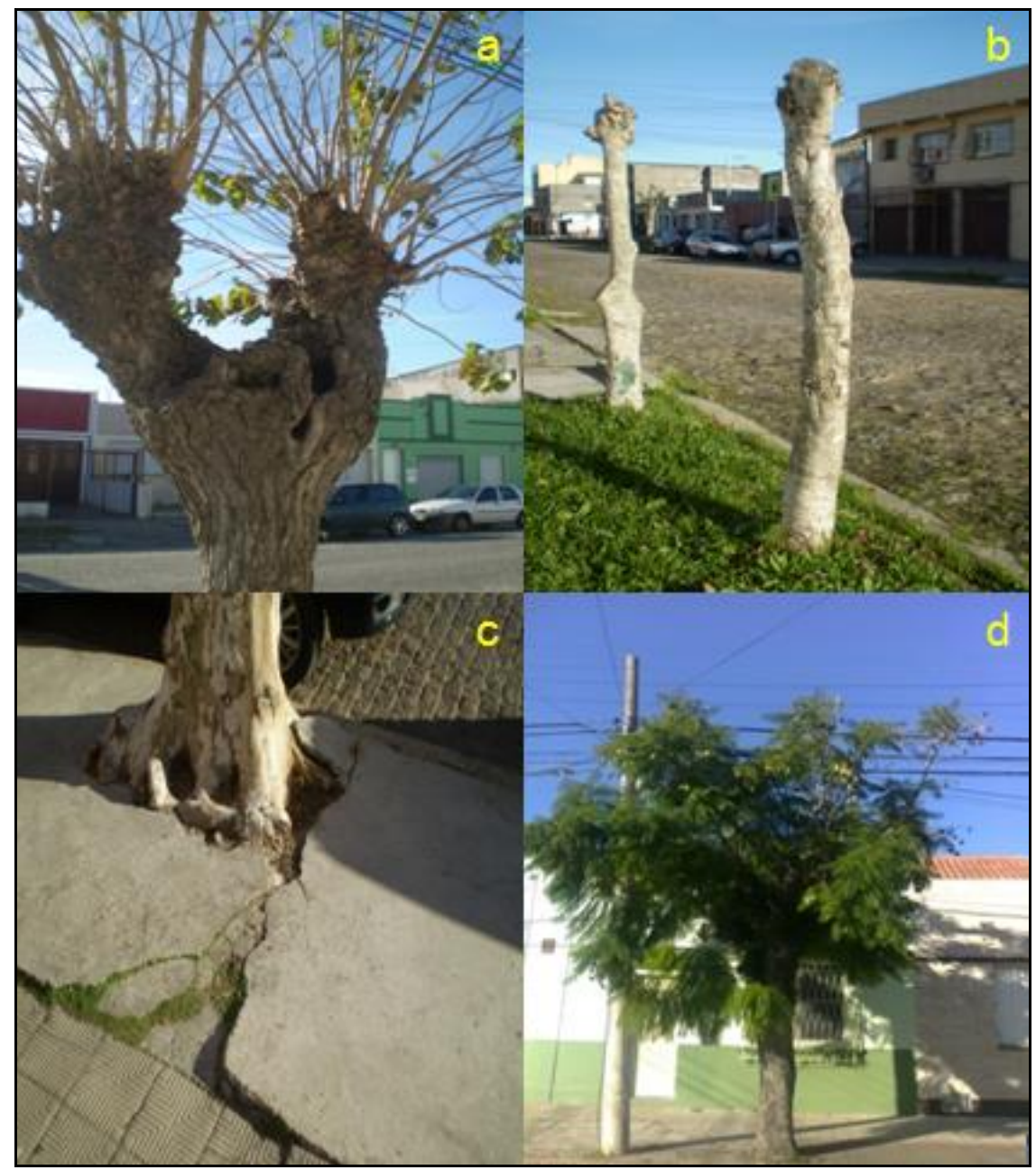

Figura 3. Formação de ramosepicórmicos em $P$. nigra (a); indicação de poda drástica em $S$. cumini (b); conflito do sistema radicular de $P$. acerifolia com a pavimentação da calçada (c); interferência na fiação aérea do J. mimosifolia (d)

Figure 3. Formation of epicormics branches in P. nigra (a); drastic pruning indication in S. cumini (b); conflict of the root system of $P$. acerifolia with the sidewalk paving (c); interference in the aerial wiring of $J$. mimosifolia (d)

Além das espécies citadas, destaca-se Ficus benjamina, bem conhecida na literatura por seus conflitos com a pavimentação. Apesar de ser muito cultivada em parques, jardins, e na arborização urbana, sendo muito tolerante à poda (LORENZI, et al., 2003), não é adequada para vias públicas, pois pode ocasionar problemas como rachaduras no calçamento e em construções, devido ao crescimento de suas raízes.

Essa planta é comumente vendida nas floriculturas dentro de vasos, porém, devido ao seu crescimento excessivo, não raro há o transplante desta, feito pelos próprios moradores, para locais disponíveis em frente a suas residências (aspecto observado durante a realização deste estudo), o que pode futuramente comprometer calçadas, muros e redes de água e esgoto, devido à agressividade do sistema radicular da espécie, como 
reportado; este aspecto demanda a conscientização da população para que evite esta prática, de forma a preservar as estruturas urbanas públicas e privadas.

Nesse sentido, Salvi et al. (2011) ressaltam a importância de haver planejamento adequado quanto à escolha das espécies utilizadas na arborização dos passeios públicos. Assim, devemos priorizar aquelas que possuem raízes pivotantes e profundas, evitando as superficiais, como forma de preservar a integridade das vias públicas e das redes de água e esgoto.

O diagnóstico dos lados com fiação nas ruas amostradas apontou que 52,3\% das árvores apresentaram conflitos com a rede aérea (Figura 3d). Este conflito pode estar relacionado tanto ao grande porte quanto à ampla copa das espécies dominantes, como Platanus $x$ acerifolia, Jacaranda mimosifolia, Populus nigra e Melia azedarach. Um manejo adequado destas árvores em seu estágio juvenil poderia possibilitar o seu crescimento de forma a liberar a passagem dos fios entre os galhos, prevenindo podas severas em indivíduos adultos e evitando, assim, prejuízos à fitossanidade das plantas, e às características arquitetônicas de suas copas.

Entre as espécies citadas, Jacaranda mimosifolia foi responsável pela maior parte dos conflitos com a fiação aérea na área amostrada (42\%), seguido por uma espécie de copa ampla, Platanus $x$ acerifolia (21,7\%). Isso pode ser explicado tanto em função de o jacarandá-mimoso ser a espécie mais abundante registrada no inventário, quanto em razão do porte e das características de sua copa. Segundo Lorenzi et al. (2003), embora a espécie possa ser também utilizada na arborização urbana, o seu plantio é adequado para grandes jardins. Tendo em vista os conflitos apresentados, uma solução seria buscar a substituição gradual destas árvores por outras que tenham menor interferência na infraestrutura urbana.

No presente estudo há predominância $(81 \%)$ de indivíduos arbóreos de grande porte, entre os quais se destacam Platanus $x$ acerifolia, Populus nigra e Jacaranda mimosifolia. As árvores de porte médio, como Schinus terebinthifolius, representaram 11,9\% do total e as de pequeno porte 6,9\%. Embora muitos autores defendam o plantio de árvores de pequeno porte como forma de evitar conflitos com a fiação aérea e a pavimentação dos passeios públicos, a utilização de indivíduos arbóreos de grande porte, quando bem planejada e executada, fazendo uso adequado da técnica de poda ou a utilização de fiação ecológica proporciona melhor aproveitamento das inúmeras vantagens que as plantas maiores oferecem em comparação àquelas de pequeno porte, como sombreamento, influência positiva no microclima urbano, redução da temperatura e dos poluentes atmosféricos e aumento da umidade do ar.

As árvores de grande porte podem ser utilizadas sob a rede aérea, quando houver espaço suficiente para o seu desenvolvimento, reduzindo a possibilidade de problemas e a 
necessidade de poda. Estas árvores são vantajosas em relação às de pequeno porte, já que estas últimas podem oferecer risco de acidentes, conflitar com placas de sinalização, semáforos, além de serem mais suscetíveis ao vandalismo contra galhos e ramos.

Ressalta-se que, em vista das vantagens e desvantagens associadas ao porte das árvores que irão compor a arborização das vias públicas, seja qual for a escolha no momento do planejamento, deve-se sempre considerar a recomendação de fornecer espaço suficiente para desenvolvimento das árvores, bem como investir na adequação da infraestrutura das cidades para receber as árvores com o mínimo de conflito possível. Nesse sentido, Aguirre Junior, Volpe-Filik e Lima (2007) afirmaram que o poder público municipal deveria repensar e substituir as redes convencionais, priorizando as fiações de rede compacta e subterrânea, de forma a eliminar a poluição visual, e evitar a necessidade de suprimir e mutilar constantemente por meio da poda as árvores para que não interfiram nas fiações, o que provoca a deformação de suas copas, quedas, problemas fitossanitários e a redução dos benefícios ambientais associados à cobertura vegetal.

As médias ponderadas totais da distância do início da rua (medida do início de cada quadra) até a primeira árvore (DIRPA) e distância da última árvore até o final da rua (DUAFR - medida da última árvore da quadra até o final desta) apresentaram os valores 27,58m e 24,8 m, com desvio padrão de 27,30 m e 25,02 m, respectivamente (Quadro 1), os quais foram influenciados pela existência de quadras com uma única ou poucas árvores, gerando extensos espaços desarborizados, o que sugere a inexistência de um projeto estruturado de arborização.

No entanto, os valores estão de acordo com o recomendado pelo Plano Diretor de Arborização Urbana de Porto Alegre (SMAM, 2007), que aconselha a distância mínima de 5 $\mathrm{m}$ entre a árvore e a esquina, para evitar a interferência com o tráfego de veículos e não afetar a visibilidade dos motoristas. O Plano Diretor recomenda também a distância 3 a 6 metros entre uma árvore e outra dependendo do seu porte, para evitar conflitos entre os indivíduos e possibilitar seu desenvolvimento. A média ponderada da distância em relação à árvore posterior (DRAP) encontrada neste estudo foi 10,83 m (desvio padrão de 11,38 m); está, portanto, acima do recomendado pelo Plano Diretor. 


\begin{tabular}{|c|c|c|c|c|c|c|c|c|}
\hline $\begin{array}{c}\text { Vias } \\
\text { Públicas }\end{array}$ & 인 $\frac{\substack{0 \\
\frac{0}{2}}}{\frac{0}{2}}$ & 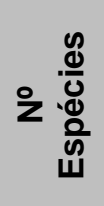 & $\begin{array}{l}\text { DMF } \\
\text { (m) }\end{array}$ & $\begin{array}{l}\text { DRAP } \\
\text { (m) }\end{array}$ & $\begin{array}{c}\text { DICPA } \\
(\mathrm{m})\end{array}$ & $\begin{array}{c}\text { DUAFC } \\
(\mathrm{m})\end{array}$ & $\begin{array}{c}\text { DIRPA } \\
(\mathrm{m})\end{array}$ & $\begin{array}{l}\text { DUAFR } \\
(\mathrm{m})\end{array}$ \\
\hline $\begin{array}{c}\text { General } \\
\text { Abreu }\end{array}$ & 87 & 22 & 0,44 & 13,3 & 3,73 & 2,06 & 19,03 & 42,38 \\
\hline $\begin{array}{l}\text { Visconde } \\
\text { de Mauá }\end{array}$ & 38 & 21 & 0,5 & 8,84 & 6,18 & 2,04 & 46,74 & 32,55 \\
\hline $\begin{array}{c}\text { Marechal } \\
\text { Deodoro }\end{array}$ & 138 & 16 & 0,29 & 10,76 & - & - & 8,45 & 9,57 \\
\hline República & 48 & 23 & 0,57 & 10,4 & - & - & 41,12 & 23,38 \\
\hline TOTAL & 311 & 34 & 0,4 & 10,83 & 4,43 & 2,05 & 27,58 & 24,8 \\
\hline
\end{tabular}

DMF: distância do meio fio; DRAP: distância em relação à árvore posterior; DICPA: distância do início do canteiro até a primeira árvore; DUAFC: distância da última árvore até o final do canteiro; DIRPA: distância do início da rua até a primeira árvore; DUAFR: distância da última árvore até o final da rua.

Quadro 1. Número de indivíduos e a riqueza específica por rua, bem como as médias de DMF, DRAP, DICPA, DUAFC, DIRPA, DUARF

Chart 1. Number of individual sand species richness by street, as well as the averages of the CAP, DMF, DAP, DICPA, DUAFC, DIRPA, DUARF

A distância média das árvores em relação à face interna do meio-fio foi de 0,4 m, com desvio padrão de 0,25 m (Quadro 1); o Plano Diretor de Arborização Urbana de Porto Alegre (SMAM, 2007) recomenda a distância de 0,6 m entre as árvores e o meio-fio, a fim de protegê-las de danos físicos ocasionados por veículos automotores. Além dessa distância mínima, é fundamental o plantio de espécies adequadas ao espaço físico disponível para preservar a saúde das árvores e a integridade da estrutura urbana. As informações referentes à distância do colo das árvores em relação ao meio-fio estão relacionadas com as condições de plantio e possíveis problemas para a calçada, indicando também a necessidade de cuidados especiais em relação a estas árvores.

Das árvores amostradas, apenas $18,3 \%$ são jovens, e as demais, adultas. Árvores adultas necessitam de cuidados especiais, através de programas de manejo adequado, a fim de manter sua saúde e reduzir conflitos com a infraestrutura urbana.

Verificou-se importante variação na distribuição dos indivíduos em cada via pública, indicando falta de critérios no planejamento da arborização, pois na Rua Marechal Deodoro foi encontrada a maior parte das árvores amostradas (Quadro 1), assim como a menor riqueza específica, com a predominância de apenas uma espécie arbórea exótica. Isso sugere ao poder público a adoção de critérios, para o plantio de árvores e o manejo das já existentes, que possam aliar a diversidade de espécies, evitando a homogeneização associada a riscos sanitários e desequilíbrio ecológico, bem como a distribuição equilibrada da arborização entre as vias públicas, a fim de que os benefícios inerentes à presença de vegetação sejam potencializados. 


\section{CONCLUSÕES}

Neste estudo, observou-se elevada homogeneização da arborização nas ruas inventariadas, devido à dominância das espécies exóticas Platanus $x$ acerifolia e Jacaranda mimosifolia. A condição fitossanitária das árvores amostradas foi considerada boa, com exceção da existência de ramos epicórmicos, indicando manejo inadequado das árvores com relação ao procedimento de poda. Conflitos com a fiação aérea e a pavimentação dos passeios públicos também foram relevantes, sugerindo atentar para a adequação das espécies ao espaço urbano disponível, repensando as formas de manejo da vegetação, e desenvolvendo estratégias que melhorem a condição fitossanitária das árvores e sua interação com a infraestrutura urbana, como o uso de cabos de energia ecológicos, além de investir na diversificação de espécies, principalmente naquelas nativas da região, a fim de assegurar a sustentabilidade e a qualidade ambiental no município. O estudo realizado indica também a importância do diagnóstico das interações entre a vegetação e o espaço urbano disponível, como forma de garantir um manejo adequado da arborização já existente, mas também para subsidiar futuros projetos nesse sentido.

\section{REFERÊNCIAS}

AGUIRRE JUNIOR, J. H.; VOLPE-FILIK, A.; LIMA, A. M. L. P. Programa amiga árvore: plantio de árvores em vias públicas na cidade de Piracicaba/SP. Revista da Sociedade Brasileira de Arborização Urbana, Piracicaba-SP, v. 2, n. 2, p. 46-64, 2007.

ALMEIDA, D.N.; NETO, R.M.R. Análise da arborização urbana de duas cidades da região norte do estado de Mato Grosso. Revista Árvore, Viçosa-MG, v.34, n.5, p.899-906, 2010. ANDRADE, T. O. Inventário e análise da arborização viária da Estância Turística de Campos de Jordão, SP. Piracicaba, SP, 2002. 112f. Dissertação (Mestrado em Agronomia) - Escola Superior de Agricultura, Universidade de São Paulo.

ANGIOSPERM PHYLOGENY GROUP. An update of the Angiosperm Phylogeny Group classification for the orders and families of flowering plants. APG III. Botanical Journal Linnean Society, Londres, v. 161, p. 105-121, 2009.

BARROS, E.F.S.; GUILHERME, F.A.G.; CARVALHO, R.S. Arborização urbana em quadras de diferentes padrões construtivos na cidade de Jataí. Revista Árvore, Viçosa-MG, v.34, n.2, p.287-295, 2010.

BATISTEL, L. M.; DIAS, M. A. B.; MARTINS, A. S.; RESENDE, I. L. M. Diagnóstico qualitativo e quantitativo da arborização urbana nos bairros Promissão e Pedro Cardoso, Quirinópolis, Goiás. Revista da Sociedade Brasileira de Arborização Urbana, PiracicabaSP, v. 4, n. 3, p. 110-129, 2009. 
BOBROWSKI, R.; BIONDI, D. Distribuição e dinâmica da área de copa na arborização de ruas de Curitiba, Paraná, Brasil, no período de 1984-2010. Revista Árvore, Viçosa-MG, v.36, n.4, p.625-635, 2012.

CALIXTO JÚNIOR, J. T.; SANTANA, G. M.; LIRA FILHO, J. A. Análise quantitativa da arborização urbana de Lavras da Mangabeira, CE, Nordeste do Brasil. Revista da Sociedade Brasileira de Arborização Urbana, Piracicaba-SP, v.4, n.3, p.99-109, 2009.

INTERNATIONAL SOCIETY OF ARBORICULTURE. Disponível em: <http://www.isaarbor.com/>. Acesso em: 29 ago. de 2015.

JACOBI, U.S.; DUARTE, C.I.; GONÇALVES, R.S.; ACUNHA, J.S.; HEFLER, S.M. Florística dos ecossistemas do Campus Carreiros, Rio Grande, Rio Grande do Sul, Brasil. Iheringia, Sér. Bot., Porto Alegre-RS, v. 68, n. 1, p. 73-89, 2013.

KRAMER, J.A.; KRUPEK, R.A. Caracterização florística e ecológica da arborização de Praças Públicas do Município de Guarapuava, PR. Revista Árvore, Viçosa-MG, v.36, n.4, p.647-658, 2012.

LORENZI, H. Espécies nativas e exóticas na arborização urbana. In: ENCONTRO NACIONAL DE ARBORIZAÇÃO URBANA, VIII 1999, Fortaleza; FEIRA NORDESTINA DE ECOLOGIA E MEIO AMBIENTE, 1a, 1999. Anais. Fortaleza: Sociedade Brasileira de Arborização Urbana, 1999.

LORENZI, H.; SOUZA, H. M.; TORRES, M. A. V.; BACHER, L. B. Árvores exóticas no Brasil: madeireiras, ornamentais e aromáticas. São Paulo: Instituto Plantarum, 2003.

LORENZI, H. Árvores brasileiras: manual de identificação e cultivo de plantas arbóreas do Brasil. 6 ed. v.1. Nova Odessa, São Paulo: Instituto Plantarum, 2014a.

LORENZI, H. Árvores Brasileiras - manual de identificação e cultivo de plantas arbóreas nativas do Brasil. 4 ed. v. 2. Ed. Nova Odessa, São Paulo: Instituto Plantarum. 2014b.

MELO, R. R.; LIRA FILHO, J. A.; RODOLFO JÚNIOR, F. Diagnóstico qualitativo e quantitativo da arborização urbana no Bairro Bivar Olinto, Patos, Paraíba. Revista da sociedade Brasileira de arborização Urbana, Piracicaba-SP,v. 1, n. 1, p. 64-80, 2007.

PALAZZO JUNIOR, J. T.; BOTH, M. do C. A natureza no jardim: um guia prático de jardinagem ecológica e recuperação de áreas degradadas. Porto Alegre: Sagra, 1989.

RABER, A. P; REBELATO, G. S. Arborização viária do município de Colorado, RS - Brasil: análise quali-quantitativa. Revista da Sociedade Brasileira de Arborização Urbana, Piracicaba-SP,v.5, n.1, p.183-199, 2010.

ROMANI, G.N.; GIMENES, R.; SILVA, M.T.; PIVETTA, K.F.L.; BATISTA, G.S. Análise qualiquantitativa da arborização na Praça XV de Novembro em Ribeirão Preto - SP, BRASIL. Revista Árvore, Viçosa-MG, v.36, n.3, p.479-487, 2012.

ROPPA, C.; FALKENBERG, J. R.; STANGERLIN, D. M.; BRUN, F. G. K.; BRUN, E. J.; LONGHI, S. J. Diagnóstico da percepção dos moradores sobre a arborização urbana na Vila Estação Colônia - Bairro Camobi, Santa Maria-RS. Revista da Sociedade Brasileira de Arborização Urbana, Piracicaba-SP, v. 2, n. 2, p. 11-30, 2007. 
SALVI, L.T.; HARDT, L.P.A.; ROVEDDER, C.E.; FONTANA, C.S. Arborização ao longo de ruas túneis verdes em Porto Alegre, RS, BRASIL: avaliação quantitativa e qualitativa. Revista Árvore, Viçosa-MG, v.35, n.2, p.233-243, 2011.

SECRETARIA MUNICIPAL DO MEIO AMBIENTE (SMMA). Plano diretor de arborização urbana de Porto Alegre, 2007. Disponível em: http://www2.portoalegre.rs.gov.br/smam /default.php?p_secao=9. Acesso em: 27 ago. 2015.

SILVA, L. M.; HASSE, I.; CADORIN, D. A.; OLIVEIRA, K. A.; OLIVEIRA, F. A. C.; BETT, C. F. Inventário da arborização em duas vias de Mariópolis/PR. Revista da Sociedade Brasileira de Arborização Urbana, Piracicaba-SP, v. 3, n. 1, p. 36-53, 2008a.

SILVA, M. D. M.; SILVEIRA, R. P.; TEIXEIRA, M. I. J. G. Avaliação da arborização de vias públicas de uma área da região oeste da cidade de Franca/SP. Revista da Sociedade Brasileira de Arborização Urbana, Piracicaba-SP, v.3, n.1, p.19-35, 2008b.

SOUZA, A.L.; FERREIRA, R.A.; MELLO, A.A.; PLÁCIDO, D.R.; SANTOS, C.Z.A.; GRAÇA, D.A.S.G.; JÚNIOR, P.P.A.; BARRETTO, S.S.B.; DANTAS, J.D.M.; PAULA, J.W.A.; SILVA, T.L.; GOMES, L.P.S. Diagnóstico quantitativo e qualitativo da arborização das praças de Aracaju, SE. Revista Árvore, Viçosa-MG, v.35, n.6, p.1253-1263, 2011. 